\title{
The European Association for Sports Dentistry, Academy for Sports Dentistry, European College of Sports and Exercise Physicians consensus statement on sports dentistry integration in sports medicine
}

\author{
Athanasios Stamos $^{1,2}$ | Steve Mills ${ }^{3}$ | Nikos Malliaropoulos ${ }^{1,2}$ | Sophie Cantamessa ${ }^{1}$ | \\ Jean-Luc Dartevelle $e^{1,2}$ | Elif Gündüz ${ }^{1,2,3}$ (D) | Jeffrey Laubmeier ${ }^{3}$ | Jeffrey Hoy ${ }^{3}$ | \\ Georgios Kakavas $^{1,2}$ | Sébastien Le Garrec ${ }^{1,2}$ | Jean-François Kaux ${ }^{1,2}$ | \\ Mourad Ghrairi $^{1,2}$ | Heinz Lohrer ${ }^{1,2}$ | Marc Engels-Deutsch ${ }^{1}$ (iD
}

${ }^{1}$ European Association for Sports Dentistry (EA4SD), Rambouillet, France

${ }^{2}$ European College for Sports and Exercise Physicians (ECOSEP), Thessaloniki, Greece

${ }^{3}$ Academy for Sports Dentistry (ASD),

Springfield, IL, USA

\section{Correspondence}

Marc Engels-Deutsch, CHR METZTHIONVILLE, Hôpital de Mercy, Service d'Odontologie, 1 allée du Château CS 45001, Metz Cedex 3 F-57085, France. Email: marc.engels-deutsch@univ-lorraine.fr

\begin{abstract}
Sports medicine has a multidisciplinary character which allows different medical specialties to investigate the prevention, etiology, and treatment of athletes' diseases. This leads to a decreased risk of injury and a faster return to play as well as an improvement in the overall health and well-being of athletes of any level and in all sports around the world. The oral health of athletes is now the subject of great attention internationally because of the increased prevalence and incidence of health issues such as dental caries and erosion, periodontal disease, defective occlusion, temporomandibular joint disorders, and orofacial injuries. Scientific evidence and research on these issues have also intensified over recent years. The best way to maintain player's health and performance is to include oral health in sports medicine with physicians and dentists working closely together at the individual level as well as with the cooperation between local and international sports medicine and dentistry associations. The European Association for Sports Dentistry, the Academy for Sports Dentistry, and the European College of Sports and Exercise Physicians are leading the way and have worked together to develop a consensus statement describing the main pillars of oral health integration into sports medicine based on the most common oral diseases found in athletes and linked to exercise, sports, and performance.
\end{abstract}

KEYWORDS

consensus statement, sports dentistry, sports medicine

\section{1 | INTRODUCTION}

The European Association for Sports Dentistry (EA4SD) and the Academy for Sports Dentistry (ASD) are strongly committed to the development of sports dentistry and its integration into sports 
diseases and injuries through exercise and specialized physicians. The EA4SD, ASD, and ECOSEP are working together to promote and to provide the best possible care to professional athletes and the general public. At the 6th ECOSEP International Congress and the 1st International EA4SD Symposium held in INSEP, Paris, France, from 29 to 30 November 2019, these associations mutually agreed to develop a consensus statement on oral health in sports. The goal of this consensus statement is to call for the importance of good oral health, oral diseases, and dental function to be recognized as relevant factors influencing overall health, performance, and injury risk of athletes of all levels around the world. The philosophy of the International Conference was to bring together sports physicians and dentists from international scientific communities and to give them the opportunity to showcase important studies connecting oral health and sports medicine. Both communities unanimously agreed to the new basic principles on how to integrate sports dentistry into sports medicine, based on scientific research outcome of recent years.

The new consensus statement also showcases the compelling reasons for integrating sports dentistry into sports medicine, and the strong will from both disciplines to support this effort by defining new goals and promoting further research. This consensus statement is a major positive outcome of this conference.

\section{2 | EPIDEMIOLOGY}

The oral health status can have a direct impact on the overall health, ${ }^{1}$ performance, and risk of injury ${ }^{2-4}$ in individuals who participate in sports. For example, gingivitis and periodontitis are two of the most common conditions affecting humans, and athletes are exposed to the same risk factors. ${ }^{5}$ Around the world, billions of people are participating in sports at various levels-for example, professional, amateur, or recreational. The goals of physical exercise and sports are to improve health, well-being, and, ultimately, athletic performance.

The development of sports medicine in recent years has contributed to healthier athletes and better performances. Sports medicine has also evolved into a multidisciplinary field in which sports dentistry is expected to be a key element.

Additionally, the medications prescribed or administered by dentists may affect performance or be classified as banned substances by anti-doping authorities. ${ }^{6}$

The integration of dentistry into sports medicine should focus on the most common diseases found in athletes, including dental caries, dental erosion, periodontal disease, malocclusion, temporomandibular disorders (TMD), orofacial injuries, and their prevention. This integration should lead to a multidisciplinary follow up of athletes including oral screening and relevant oral health treatments. Sports dentists should be part of the sports medical team and work alongside other medical specialties prior to the evaluation, diagnosis, and restoration of the oral health within a strict framework set by the athletes' demanding physical exercise, training sessions, games, return to play, and sports medicine principles.

\section{3 | CURRENT ORAL HEALTH OF ATHLETES}

Oral health has performance impacts in elite and professional athletes, in particular dental caries, erosive tooth wear and periodontal health. ${ }^{7}$

\subsection{Caries and dental erosion}

Dental caries is a biofilm-mediated, sugar-driven, multifactorial, dynamic disease that results in the demineralization and remineralization of dental hard tissues. Numerous surveys have shown an increased incidence of caries in athletes of all levels, especially those practicing at the professional level. ${ }^{7-9}$

The alarmingly high incidence of dental caries in athletes is associated with a high risk of tooth decay, fracture, and loss. This can result in emergency situations such as pain and abscess, and can subsequently lead to altered dental occlusion and incomplete dentitions. The athlete's diet, which is known to be very rich in carbohydrates and proteins, lowers the $\mathrm{pH}$ of the oral cavity and this in turn raises the risk of dental caries. ${ }^{10}$

Dental caries represents the most widespread non-communicable disease (NCD) worldwide according the $\mathrm{WHO}^{11}$ Athletes are not an exception and factors such as their diet further increase their risk and prevalence of caries. The use of specific dietary patterns by elite athletes induces changes in the oral microbiota, in particular Streptococcus spp. which is known to induce caries. ${ }^{12-14}$ Deep caries is suspected to have significant effects on the anaerobic performance of athletes, for example by blood parameter variations. ${ }^{15}$ The acidic diet of elite athletes is consistent with a high-risk profile for caries and erosion. ${ }^{16,17}$

Sports dentistry's efficient integration into sports medicine will allow the sports dentists to provide better oral hygiene advice, to diagnose and treat dental caries in a timely manner and to avoid complications such as apical periodontitis and its association with systemic diseases. ${ }^{18}$ This cooperation with sports physicians and other professionals such as general dentists, endodontists, periodontists, oral and maxillofacial surgeons, and radiologists for cone beam computed tomography ${ }^{19-21}$ when needed, will significantly improve athletes' oral and overall health.

\section{2 | Periodontal disease}

Periodontal disease is a chronic inflammatory disease of the periodontium. In its advanced form, it is characterized by periodontal ligament loss and destruction of the surrounding alveolar bone. Epidemiological data and numerous studies have shown a high incidence of periodontal disease in athletes due to their physical exercise and sports activity, similar to caries. ${ }^{9,11}$ Poor periodontal status increases serum creatine kinase levels, leading to possible muscular and/or heart damage among young soccer players. ${ }^{22}$ Periodontal disease (and dental caries) influences athlete's performance negatively, particularly by affecting the respiratory system. ${ }^{23}$ 
Acute or chronic periodontal conditions can lead to tooth mobility, tooth loss, presence of inflammation, and abscesses in the oral cavity. Modern life, regular healthy diet, and sugar consumption affect the oral microbiome resulting in a dysbiosis which disturbs the ecologically balanced biofilm that can cause diseases in the oral or other tissues. ${ }^{24,25}$ For example, periodontal disease can increase the risk of diabetes $^{26-28}$, and musculo-tendinous overuse injuries are prevalent in people with type 2 diabetes. ${ }^{29}$ Periodontal disease has been shown to impair muscle recovery in an animal experimental model. ${ }^{30}$

Additionally, bacteria and their endotoxins have a direct entrance into the bloodstream from the periodontium and thus can easily migrate into other parts of the body, such as the heart, lungs, joints, and sites of recent operations. ${ }^{31,32}$

Athletes' diet and stress also increase the risk of periodontal disease. Stress-related endocrine changes, neglect of oral hygiene, changes in dietary intake, altered gingival blood circulation, and decreased salivary flow are all factors associated with gingival diseases. All of the above conditions are commonly found in athletes and are linked to physical exercise. ${ }^{33}$

It is highly important that sports dentists establish an early diagnosis by screening for periodontal diseases in athletes so they can then plan and provide the necessary treatment in a timely fashion.

\section{3 | Occlusion/Temporomandibular joint}

The dental occlusion and the function of the temporomandibular joint (TMJ) have great importance in the functioning and health of the overall stomatognathic system. This in turn can have an impact on the function of the body and can influence physical exercise, injury risk, and performance of athletes. ${ }^{34,35}$ When studying the field of functional neurology in sports and its prevention, it is clear that the stomatognathic system is a part of the nervous system that might affect posture, strength, and coordination in athletes. ${ }^{36-38}$

The neurology behind injury mechanisms is a hot topic for the future in Sports Medicine and Dentistry. It is important to re-evaluate the way the most common injuries such as hamstrings, $A C L$, groin pain, ankle sprains, and many more are assessed.

With the cooperation between sports dentistry and medicine, sports dentists will diagnose and treat defective dental occlusion and temporomandibular disorders for the benefit of athletes' oral and overall health. The athlete's body should be considered as a "whole," and health practitioners should become more holistic and work as an interdisciplinary team of sports medicine and dentistry practitioners.

\section{4 | Orofacial injuries protection}

Orofacial injuries are very frequent in sports, especially in contact sports. $^{39}$
Studies have linked sports to nearly one third of all dental injuries. Furthermore, one in six sports-related injuries is to the craniofacial area. In 2000, the US Surgeon General's report on oral health identified sporting activities as one of the "principal causes of craniofacial injuries". ${ }^{40}$ In the United States alone, dental injuries from recreational sports account for more than 600000 emergency dental visits each year.

Prevention should be based on the fabrication by sports dentists of custom-made properly fitted mouthguards ${ }^{41}$ for their shock absorption capacities ${ }^{42,43}$ respecting the individual athlete anatomical and functional characteristics. The role and effect of custom-made mouthguards has been the subject of extensive research in sports dentistry. ${ }^{44,45}$

Sports dentists become necessary to take all preventive measures for orofacial injuries caused by sports. Sports physicians will have one less important issue for athletes to deal with, and athletes will benefit from proper protection of their orofacial region while practicing sports.

\section{4 | SPORTS MEDICINE PERSPECTIVE}

Sports medicine now has a multidisciplinary character. It means that different medical specialties are working together in both the diagnosis and treatment of athletes' health issues in order to achieve the best prevention and outcome of the medical assessment. ${ }^{46}$ The integration of sports dentistry will contribute to the prevention, screening and treatment of dental caries, dental erosion, periodontal disease, malocclusion, and TMD and other injury. This in turn will provide all athletes with better oral and overall health and well-being. It can also significantly decrease the risk of systemic diseases and musculoskeletal injuries as well as enhance performance.

Practicing sports can affect the oral health through dehydration, stress, bruxism (teeth grinding), tooth erosion, and abrasion. Athletes' diets that are rich in sugars and acids in sports foods and beverages ${ }^{47}$ cannot change but the consequences of this diet can be monitored and controlled by sports dentists. Physical impacts can cause orofacial injuries, altered dental occlusion and TMD. The stomatognathic system is part of the musculoskeletal system of the body and is directly connected with it through the nervous system. Thus, it is time to have a closer look into its conditions that can influence the athlete's overall health. For example, dentists must be included in the management of periodontal and associated systemic diseases, as part of a multidisciplinary approach. ${ }^{48}$ Sports physicians and medical professionals should be aware of the health risks that oral diseases and conditions represent, and work together with sports dentists. Moreover, awareness of the issues of oral health in elite sport must be improved. Prevention, promotion of good health and research strategies must be developed. ${ }^{49}$ Furthermore, athletes must be willing to consider behavior change to improve their oral health. ${ }^{50}$ 


\section{5 | GOALS}

The purpose of the common EA4SD, ASD, and ECOSEP consensus statement is to highlight the need for integrating sports dentistry into sports medicine. Sports dentists can be valuable members of the sports medical team, and the joint efforts to provide better prevention and health to athletes will benefit the overall medical assessment of athletes' health.

Dental screening will be part of the standard medical screens of athletes, and research about oral health and body inter-relationship will be increased. The international sports federations are encouraged to support this idea, and sports medical centers will be asked to implement the sports dentistry integration.

\section{6 | CONCLUSION}

It is now desirable to integrate sports dentistry into the sports medicine multi-disciplinary field. ${ }^{39}$ Sports dentistry has recently been recognized as a new field in dentistry by the World Dental Federation (FDI) by supporting and publishing the first ever sports dentistry guidelines and toolkit addressed to athletes (2019), to the general population, dentists, sports physicians, sports federations, and associations as well as medical centers. ${ }^{51}$ Research on sports dentistry is increasing considerably, and academic integration at dental faculties is progressing. There is a complex two-way interaction between oral health and physical exercise, and it is clear that oral diseases can influence physical exercise outcome, risk of injury, and performance. Physical exercise seems to be a risk factor for initiating or aggravating oral diseases because of factors such as stress, diet, salivary flow, absence of oral health prevention, and protection against orofacial injuries. There is a pressing need for efficient integration of sports dentistry into sports medicine, for promotion of research on the impact of the stomatognathic system on body exercise and for raising awareness of the importance of oral health in sports within the athletic community, health professionals, sports federations, and medical centers.

\section{ACKNOWLEDGEMENTS}

This Consensus Statement is dedicated to the memory of Dr Richard Knowlton, for his help to establish this statement who passed away suddenly in March 2020.

\section{CONFLICT OF INTEREST}

The authors confirm that they have no conflict of interest.

\section{ORCID}

Elif Gündüz (iD https://orcid.org/0000-0002-1080-3160

Marc Engels-Deutsch iD https://orcid.org/0000-0001-8514-7703

\section{REFERENCES}

1. Dörfer C, Benz C, Aida J, Campard G. The relationship of oral health with general health and NCDs: a brief review. Int Dent J. 2017;67(Suppl 2):14-8.
2. Gay-Escoda C, Vieira-Duarte-Pereira D-M, Ardèvol J, Pruna R, Fernandez J, Valmaseda-Castellón E. Study of the effect of oral health on physical condition of professional soccer players of the Football Club Barcelona. Med Oral Patol Oral Cirugia Bucal. 2011;16:436-39

3. Hadad H, Cervantes LCC, da Silva RBP, Junger B, Gonçalves PZ, Fabris $A L$, et al. Surgical treatment of anterior sinus wall fracture due to sports accident. J Craniofac Surg. 2018;29:722-23.

4. Scheffler P, Wolter NE, Namavarian A, Propst EJ, Chan Y. Contact sport related head and neck injuries in pediatric athletes. Int $J$ Pediatr Otorhinolaryngol. 2019;121:6-9.

5. Budd SC, Egea JC. Sport, periodontal consequences and athletic patients. In Sport and Oral Health. Cham, Switzerland: Springer Nature; 2017: 71-4.

6. Heuberger JAAC, Cohen AF. Review of WADA prohibited substances: limited evidence for performance-enhancing effects. Sports Med Auckl NZ. 2019;49:525-39.

7. Gallagher J, Ashley P, Petrie A, Needleman I. Oral health and performance impacts in elite and professional athletes. Community Dent Oral Epidemiol. 2018;46:563-68.

8. Borg A, Birkhed D. Dental caries and related factors in a group of young Swedish athletes. Int J Sports Med. 1987:8:234-35.

9. Needleman I, Ashley P, Petrie A, Fortune F, Turner W, Jones J, et al. Oral health and impact on performance of athletes participating in the London 2012 Olympic Games: a cross-sectional study. Br J Sports Med. 2013;47:1054-58.

10. Moye ZD, Zeng L, Burne RA. Fueling the caries process: carbohydrate metabolism and gene regulation by Streptococcus mutans. J Oral Microbiol. 2014;6:24878. https://www.tandfonline.com/doi/ full/10.3402/jom.v6.24878

11. World Health Organization. Sugars and dental caries. Available from https://www.who.int/nutrition/publications/nutrientrequire ments/sugars-dental-caries-keyfacts/en/. Accessed January 2020

12. Murtaza N, Burke LM, Vlahovich N, Charlesson B, O'Neill HM, Ross $\mathrm{ML}$, et al. Analysis of the effects of dietary pattern on the oral microbiome of elite endurance athletes. Nutrients. 2019;11:261.

13. Patterson MJ. Streptococcus. In: Baron S, editor. Medical Microbiology (4th ed). Galveston, TX: University of Texas Medical Branch at Galveston; 1996. Chapter 13. Available from https:// www.ncbi.nlm.nih.gov/books/NBK7611/. Accessed June 2020.

14. Gibbons RJ, van Houte J. Dental caries. Annu Rev Med. 1975;26:121-36

15. Hamamcılar O, Kocahan T, Akınoğlu B, Hasanoğlu A. Effect of dental caries and the consequential variation in blood parameters on the anaerobic performance of rowing athletes. Med J Islam World Acad Sci. 2019;27:55-60.

16. Bryant S, McLaughlin K, Morgaine K, Drummond B. Elite athletes and oral health. Int J Sports Med. 2011;32:720-24.

17. Sirimaharaj $\mathrm{V}$, Messer LB, Morgan M. Acidic diet and dental erosion among athletes. Aust Dent J. 2002;47:228-36.

18. Segura-Egea JJ, Martín-González J, Castellanos-Cosano L. Endodontic medicine: connections between apical periodontitis and systemic diseases. Int Endod J. 2015;48:933-51.

19. Patel S. New dimensions in endodontic imaging: Part 2. Cone beam computed tomography. Int Endod J. 2009;42:463-75.

20. Kumar M, Shanavas M, Sidappa A, Kiran M. Cone beam computed tomography - know its secrets. J Int Oral Health. 2015;7:64-8.

21. Jain S, Choudhary K, Nagi R, Shukla S, Kaur N, Grover D. New evolution of cone-beam computed tomography in dentistry: combining digital technologies. Imaging Sci Dent. 2019;49:179-90.

22. Alshail F, Aljohar A, Alshehri M. Periodontal status and serum creatine kinase levels among young soccer players: a preliminary report. Niger J Clin Pract. 2016;19:655-58.

23. Hamamcılar O, Kocahan T, Akınoğlu B, Hasanoğlu A. Effect of poor oral health on respiratory functions which is one of the 
important factor of sportive performance. Med J Islam World Acad Sci. 2018;26:74-9.

24. Hajishengallis G. Periodontitis: from microbial immune subversion to systemic inflammation. Nat Rev Immunol. 2015;15:30-44.

25. Kilian M. The oral microbiome - friend or foe? Eur J Oral Sci. 2018;126(Suppl 1):5-12.

26. Soskolne WA, Klinger A. The relationship between periodontal diseases and diabetes: an overview. Ann Periodontol. 2001;6:91-8.

27. Liccardo D, Cannavo A, Spagnuolo G, Ferrara N, Cittadini A, Rengo $C$, et al. Periodontal disease: a risk factor for diabetes and cardiovascular disease. Int J Mol Sci. 2019;20:1414.

28. Nyvad B, Takahashi N. Integrated hypothesis of dental caries and periodontal diseases. J Oral Microbiol. 2020;12:1710953.

29. de Jonge S, Rozenberg R, Vieyra B, Stam HJ, Aanstoot HJ, Weinans $\mathrm{H}$, et al. Achilles tendons in people with type 2 diabetes show mildly compromised structure: an ultrasound tissue characterisation study. Br J Sports Med. 2015;49:995-99.

30. de Souza BC, Matte BF, Lopes AL, Teixeira BC, Lamers ML. Periodontal disease impairs muscle recovery by modulating the recruitment of leukocytes. Inflammation. 2020;43:382-91.

31. Kempsell KE, Cox CJ, Hurle M, Wong A, Wilkie S, Zanders ED, et al. Reverse transcriptase-PCR analysis of bacterial rRNA for detection and characterization of bacterial species in arthritis synovial tissue. Infect Immun. 2000;68:6012-26.

32. Louhelainen A-M, Aho J, Tuomisto S, Aittoniemi J, Vuento R, Karhunen PJ, et al. Oral bacterial DNA findings in pericardial fluid. J Oral Microbiol. 2014;6:25835.

33. Goyal S, Gupta G, Thomas B, Bhat KM, Bhat GS. Stress and periodontal disease: the link and logic!! Ind Psychiatry J. 2013;22:4-11.

34. Gangloff P, Louis JP, Perrin PP. Dental occlusion modifies gaze and posture stabilization in human subjects. Neurosci Lett. 2000;293:203-6.

35. Milani RS, De Perière DD, Lapeyre L, Pourreyron L. Relationship between dental occlusion and posture. Cranio J Craniomandib Pract. 2000;18:127-34.

36. Wakano S, Takeda T, Nakajima K, Kurokawa K, Ishigami K. Effect of experimental horizontal mandibular deviation on dynamic balance. J Prosthodont Res. 2011;55:228-33.

37. Ringhof S, Hellmann D, Meier F, Etz E, Schindler HJ, Stein T. The effect of oral motor activity on the athletic performance of professional golfers. Front Psychol. 2015;6:750.

38. Dias AA, Redinha LA, Silva LM, Pezarat-Correia PC. Effects of dental occlusion on body sway, upper body muscle activity and shooting performance in pistol shooters. Appl Bionics Biomech. 2018;2018:9360103.

39. Piccininni P, Clough A, Padilla R, Piccininni G. Dental and orofacial injuries. Clin Sports Med. 2017;36:369-405.

40. U.S. Department of Health and Human Services. Oral health in America: a report of the surgeon general. Published online 2000.
Available from https://www.nidcr.nih.gov/research/data-statistics/ surgeon-general. Accessed January 2020

41. Tuna EB, Ozel E. Factors affecting sports-related orofacial injuries and the importance of mouthguards. Sports Med AuckI NZ. 2014;44:777-83.

42. Cetin C, Keçeci AD, Erdoğan A, Baydar ML. Influence of custom-made mouth guards on strength, speed and anaerobic performance of taekwondo athletes. Dent Traumatol. 2009;25: 272-76.

43. Bochnig MS, Oh M-J, Nagel T, Ziegler F, Jost-Brinkmann P-G. Comparison of the shock absorption capacities of different mouthguards. Dent Traumatol. 2017;33:205-13.

44. Green Jl. The role of mouthguards in preventing and reducing sports-related trauma. Prim Dent J. 2017;6:27-34.

45. Lloyd JD, Nakamura WS, Maeda Y, Takeda T, Leesungbok R, Lazarchik D, et al. Mouthguards and their use in sports: report of the 1st international sports dentistry workshop, 2016. Dent Traumatol. 2017;33:421-26.

46. Dvorak J, Junge A. Twenty years of the FIFA medical assessment and research centre: from "medicine for football" to "football for health". Br J Sports Med. 2015;49:561-63.

47. Hassapidou M. Carbohydrate requirements of elite athletes. $\mathrm{Br} \mathrm{J}$ Sports Med. 2011;45(2):e2.

48. Genco RJ, Genco FD. Common risk factors in the management of periodontal and associated systemic diseases: the dental setting and interprofessional collaboration. J Evid-Based Dent Pract. 2014;14(Suppl):4-16.

49. Needleman I, Ashley P, Fine P, Haddad F, Loosemore M, de Medici A, et al. Oral health and elite sport performance. Br J Sports Med. 2015;49:3-6.

50. Gallagher J, Ashley P, Petrie A, Needleman I. Oral health-related behaviours reported by elite and professional athletes. $\mathrm{Br}$ Dent J. 2019;227:276-80

51. World Dental Federation (FDI). Sports dentistry guidelines and toolkit. Available from https://www.fdiworlddental.org/resources/ toolkits. Accessed January 2020

How to cite this article: Stamos A, Mills S, Malliaropoulos N, et al. The European Association for Sports Dentistry, Academy for Sports Dentistry, European College of Sports and Exercise Physicians consensus statement on sports dentistry integration in sports medicine. Dent Traumatol. 2020;36:680-684. https://doi.org/10.1111/edt.12593 